\title{
Masculinity in Saudi Arabia Where we are and where we go from here
}

\author{
Dr.Maha MohammedNahshal \\ Assistant Professor of Social Work \\ Department of Sociology \& Social Work \\ King Abdulaziz University, Jeddah \\ Saudi Arabia
}

\begin{abstract}
Vision 2030 was introduced in 2016, with one of its aims being to empower Saudi women. Consequently, it has ushered in a Golden Age for Saudi women and there has been a wave ofcultural change,particularly with traditional gender dynamics. To shed light on this subject, this study was conducted to determine how masculinity is perceived in Saudi Arabia and how it is changing. This qualitative research involved interviewing 12 educated female participants regarding the role women themselvesplay(ed) in creating masculinity, the role of society in encouraging masculinity, and how the empowerment of women is affecting the traditional notions of masculinity. The findings indicate that whileissues of patriarchy and orthodox masculinity still persist in Saudi Arabia (in part due to Saudi women's own constructs regarding gender), Saudi female empowerment is slowly changing and challenging status quo to the extent that there is now a drive towards true equality.
\end{abstract}

Keywords: Masculinity, Vision 2030, Saudi Women

\section{Introduction}

The concept of 'masculinity' is a socially constructed ideology through which people tend to determine the actions and traits of a man in society. It is a belief held by many societies, especially among women, who consider the men to be in the dominant position. Masculinity refers to an array of traits, behaviours and attributes which are associated with the male individuals of the society. According to the diverse cultures and religious practices, the behaviours and attitudes of men vary across the whole world (Stevenson, 2018). Generally, men are not allowed to concede and compromise anything or show emotion as it is considered to be a sign of weakness.On the other hand, femininity is then determined to be the opposite of masculinity, where compromise, concession and emotions are associated with femininity and are thereforeconsidered to be weak. Hence, masculinity symbolises the dominant supremacy of men through which they are more empowered than the women.

Some scholars have categorised masculinity into different variants or types such as dominant traditional masculinity, hegemonic masculinity, oppressed traditional masculinity, subordination masculinity, precariousness manhood, marginalisation masculinity and subordination masculinity. These variants of masculinity have a substantial impact over society and mostly on the women (Elamin\&Omair, 2010). They tend to maintain dominant social roles for men, giving them authority over the females as well as on the other gender identities considered as feminine. Consequently, masculinitypropagates and determines relationships within the constructs of dominance, alliance and subordination. Therefore, masculinity serves asa predicament in that it prevents the development of women as they can only exist within the confines of femininity as determined by masculinity, which is detrimental to the evolution of society (Dobash\&Dobash, 2003).

In the context of Saudi society, gender confines and masculine supremacy are commonplace (Al-Rasheed, 2013) and thus men and women are treated differently in Saudi Society. In general, men hold positions of power and tend to dominate the women, even sometimes in space which are traditionally considereda woman's dominion. While men are expected to be the breadwinner in Saudi Arabia, the women are expected to manage household while the men remain the head of the family (Almosaed, 2008; Mobaraki\&Soderfeldt, 2010). Yet, there are many instances where even household management falls under the purview of men. Women often find themselves in positions where they are not permitted to put forth their perspectives, opinions and feelings freely nor are they allowed to move freely outside of the confines of their homes. This tends to create to an imbalance of power and authority between men and women inSaudi society. This is particularly notable in marital relationships, where male dominance can lead to suppression and oppression can lead domestic violence against the women.Masculinity is prevalent in Saudi Arabia as, in many cases, upbringing, socialisation and parenting act as factors in creating a dominant and subordinate relationship between men and women, respectively. Thus, Saudi Arabia is widely regarded as a patriarchy and masculine state. 
The issue arises not just from the way men perceive masculinity but also in the way women subconsciously and subliminally incorporate these beliefs into their own practices, attitudes into their own lives, thus perpetuating the cycle. Therefore, it is imperative to consider the role women play in encouraging masculinity as well as how masculinity needs to be address amongst men.

\section{Theoretical Framework}

To better understand the concept of masculinity, in general, it is important to understand gender structure theory. Gender structure theory considers that a given community can be divided based on gender and this division is formulated due to an array of factors such as people perceptions and social ideologies (Risman, 2017). Gender structure has three distinctive dimensions: personal, interactional and macro. These three aspects are formulated due to the effects of various factors, both cultural and material, that define the relationship between them and its manifestation into the social consciousness (Risman\& Davis, 2013). The cultural factors affect the perceptions and attitudes of society that then lean towards a gender-based community; moreover, it is reflective of thevarying ideologies held by society that affect the the concept of gender structure. The material factors are a corner stone that impact the laws, legislations promulgated by government, which can play a significant role in changing cultural views and attitudes within a gender-based society.

\section{Literature Review}

By understanding the ever-changing and vivid gender structure, it is only then possible to re-formulate the current gender structure and re-define the concept of masculinity that prevents women from acquiring equal status. The most significant harbinger for this change is to acknowledge the current social structures that reinforce masculinity and the problems that arise from it. In lieu of that, governments and legislation cannot put forth decisions that address the failings and problems, which in turn would prevent increased equality between men and women (Kenny \& Donnelly, 2018). According to MacKinnon (1989), female empowerment is essential for social development and in the context of Saudi Arabia, this is transpiring through the adoption of Vision 2030. While many feminists argue that Saudi Arabia still has some social boundaries and barriers for women in the society, the fact that they are able to proffer opinions is indicative of the changing values and attitudes towards women in Saudi society.

Until the implementation of Vision 2030, Saudi society was undoubtedly a masculine state where gender inequality manifests itself in multifarious places (Al-Rasheed, 2013). It is attributed to the eccentric and peculiar understanding of religious beliefs of the society where men are considered as the powerful and superior gender and it is widely accepted as gospel (Al-Khateeb, 1998). These attitudes were most visible in the labour force, which was dominated by men and women had next to no visibility(Mobaraki\&Soderfeldt, 2010). It is symptomatic of a masculine state where males are given high priority in almost all aspects of life, fromeducation to economics and politics (Dietz, 2003; Mobaraki\&Soderfeldt, 2010). This leads to substantial gender inequality and cultural contradiction in Saudi society (Alsaleh, 2012), whereby, when compared to women of other developing nations, Saudi women were hindered in every aspect of their lives.

With Vision 2030, the Saudi government began to make historical changes that gave women opportunities in education and employment. Private and public companies were encouraged and incentivised to employ qualified women (Saudi Vision 2030, 2016). Women are now being given the same professional opportunities as men (Sharman, 2017). Far more importantly, women now have increased autonomy as women can work without needing permission from a male guardian (Kelly, 2009; Sharman, 2017).

These developments have been made due to the involvement of women in the political sphere. In the national assembly session in Saudi Arabia, 20 women have been appointed to advise the monarchy(Loyd-Roberts,2016). Subsequently, with an increased female voice in the government, it has paved the way for the nation's social development as women are finally being utilised to their fullest potential whether it is in academics or business (Estimo Jr, 2017). These legislations are not just limited to the professional space but are permeating through the social space too as women are now allowed to legally drive and attend public social events, which were previously taboo and prohibited (Edwards, 2018).In the past, giving women freedom and autonomy was considered to erode traditional values and as wellas being 'shameful' but that attitude has begun to change with the increasing presence of women in the public sphere.

Thus, for the first time since the establishment of Saudi Arabia, social structures (e.g. governmental institutions and private companies), even if resistant, are required to include and incorporate women. Though female empowerment is in full swing and women are seeing an increase in their rights being, there has also been an adverse reaction. This has been attributed to the empowerment of women leading to challenging and destabilising the traditional dynamics and responsibilities that are connected tothe archetypal notions of masculinity and femininity. 
This can manifest itself in various forms in daily life, from the way husbands react to women taking autonomous decisions to how male staff treat a femalecustomer, and the way in which women respond to this is integral to gauge the impact of Vision 2030 and what is still needed to bring women to equal status as men.

\section{Methodology}

The qualitative research design was undertaken for this study because the subject requires an in-depth understanding of the dominating nature of the men and its impact over the women of Saudi society. The bedrock of this research is to understand the thoughts and perception of Saudi women regarding the state's decision to encourage female empowerment and autonomy. As such, qualitative research is uniquely suited for this as this approach allows for a thorough understanding of a phenomenon (Patton, 1990) with an inductive approach paving the way for more detailed, thoughtful and considered responses from the participants, thus providing a holistic picture through individual experiences (Kumar, 2005).

This research uses purposive sampling, where specific individuals are selected for the study, according to the following criteria: place, actors, event, and process (Creswell, 2006). This type of sampling also requires a predetermined location and participants and most suitable for discussing a phenomenon (Kumar, 2005). The main criteria for the sample of this study were that the participants had to be: Saudi; female; professional; mothers; and formally educated with at least an graduate degree.

Twelve participants were selected, which is sufficient to achieve data saturation for this kind of study (Marczyk, DeMatteo\& Festinger, 2005). The criterion included educated, working Saudi mothers as they are and will continue to be the vanguard of social change in the country and therefore their perception of empowerment and masculinity are essential in understanding the obstacles placed by masculinity and what improvements still need to be made.The study took place in the summer of 2019, which included a semi-structured interview with the participants. The questions focus on Saudi socialization, male monopoly in leadership, male dominance, the distinction between men and women, the difference in Saudi society's attitudes, perceptions and treatment between men and women, imbalance of gender relations and the impact of Vision 2030 on women.

In order to ensure reliability of the data (Neuman, 2010; Howitt \& Cramer, 2005), the interviews were recorded on a digital recorder, which also made it easier to revisit the interview for verification of meaning and isolating emerging themes whilst remaining true to the participants" accounts and statements. This study used "member checking" validity (Rager, 2005), and "verification" (Morse, Barrett, Mayan, Olson \& Spiers, 2002), which requires determining the accuracy of statements given, truth, and ensuring credibility of what has been recorded during a research interview (Stiles, 1993). In compliance with this, each participant was asked to review and verify their responses to ensure accuracy of the recording process and whether the statement given was the what the interviewee meant. This process provided the opportunity to address any misunderstanding or errors and re-confirm a specific aspect of the data (Stiles, 1993). It also allowed for a tentative summary of initial findings.

The method in which this research was conducted also presents limitations of the study. Firstly, the findings in this study is the perspective of only twelve participants, therefore their opinion and beliefs are not wholly a reflection of the national consensus. Furthermore, the sample size is limited to women, thus there is no masculine perspective to provide an alternative view, which could add value to the discussion of masculinity in Saudi Arabia and remove implications of bias.

\section{Findings}

As mentioned the methodology, this study focuses on five key aspects to determine the state of masculinity in Saudi Arabia: 1) male monopoly in positions of leadership and power; 2) patriarchy and the resulting male dominance; 3) the role of socialisation in constructing masculinity; 4) the imbalance in relationships between the genders; and 5) the impact that Vision 2030 has had overall.

\section{Male Monopoly in Leadership}

When the question of monopoly was presented to the interviewees, the general consensus was that it was indeed men who held power (see Figure 1). However, there were several addendums to their response. The interviewees fell into one of four categories: 1) those who believed undoubtedly that men had the monopoly; 2) though men were predominantly in positions of power, things were changing; 3) men had the right to monopolise; and 4) monopoly by men was acceptable under certain circumstances. 


\section{Figure 1:}

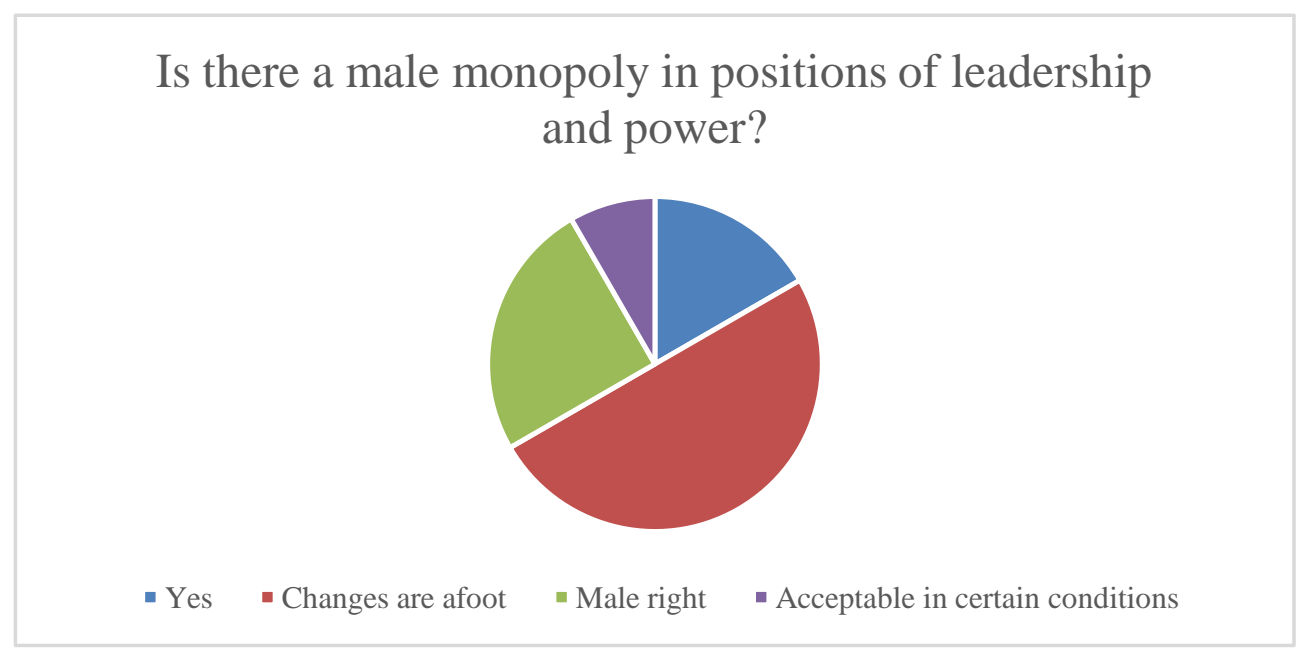

This question was accompanied by not thought-provoking responses but also some very insightful observations that could be the basis of empowerment of women in Saudi society. The first and second group represented the majority of the interviewees and it alludes to the impact of the initiatives currently in place to empower Saudi women.

On the other hand, the third and, to a lesser extent, the fourth group, presented a dilemma. Though most definitely the cumulative minority, the fact that such mindsets still exist among educated women is indicative of the challenges that Saudi society faces when it comes to female empowerment. Given that these women are educated, there are members of society who could use them as examples to deny women opportunities and positions of power, with the argument being that if these women are satisfied with their lot in life, then other women do not need to challenge or resist established practices and social structure. However, despite the barriers that these women present, it is clear that the process of change has begun in Saudi society, eventuallyleading to gender equality.

\section{Patriarchy \& Male Dominance}

To investigate the nature of patriarchy and male dominance in Saudi society, the interviewees were asked whether they felt that society encouraged and if so to what extent. The majority agreed that society supported patriarchy and male dominance, while a minority of interviewees felt that patriarchy was firmly in place, things were changing for the better (see Figure 2).

Figure 2:

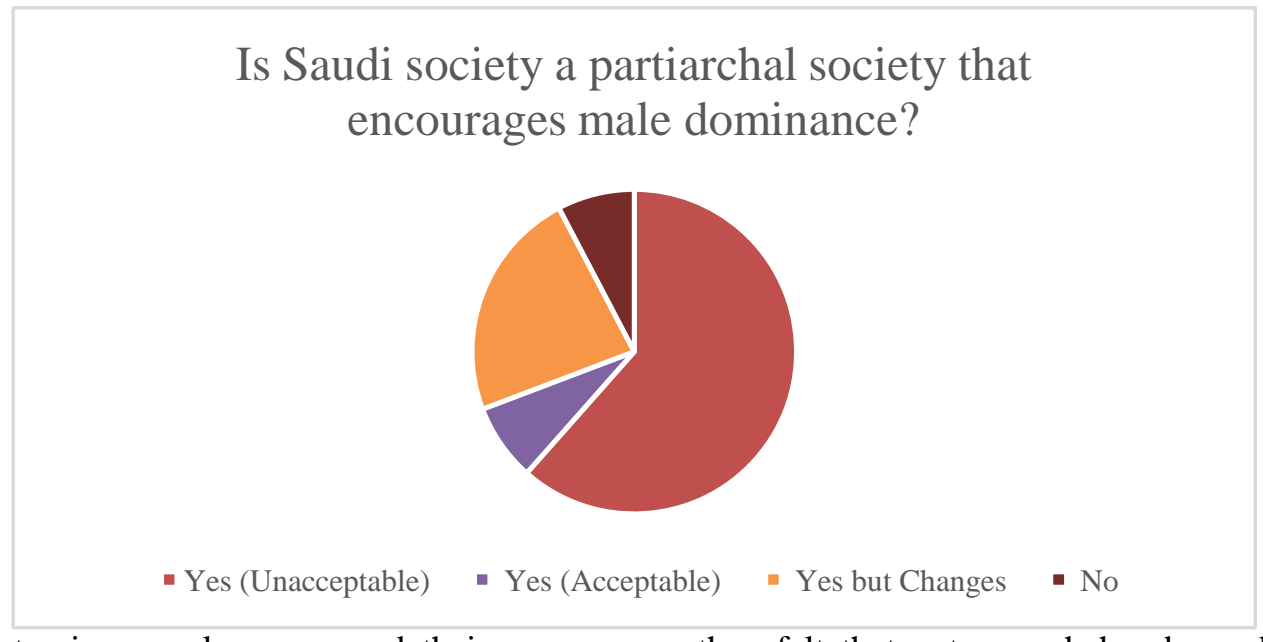

Majority of the interviewees also expressed their concerns as they felt that not enough has been done to change attitudes and consequently, women continue to suffer under the control of men. The participants cited marriage and divorce as arenas where equality was far from reality for women as men barely take responsibility for their choices and actions and women are made to suffer as a consequence.

A few of the participants felt that though patriarchy and male-dominance still persist in Saudi society, there is evidence of change and positive developments that seek to empower women and give them equal status to men. 
Their argument is that although Saudi society has a long way to go, little changes are filtering through and women are starting to gain power and therefore in time the culture will change too. Some of the participants agreed that patriarchy was very much entrenched in Saudi society but they felt that it had a positive influence and is beneficial to women. This ideology was of greater interest because their perspective tended toromanticise patriarchy without taking into consideration the extent of the damage it has done to countless generations of women. It has the potential to continue encouraging traditional forms of masculinity as theseeducated women can perpetuate unequal dynamic between men and women in generations to come.

\section{Socialisation \& Masculinity}

One of the most significant factors attributed to gender inequality is the role that socialisation, upbringing and the encouragement of masculinity in boys can play in creating gender structures that hinder women. Most of the participants agreed that the values parents instil in their sons and daughters have an enormous impact in motivating patriarchy (see Figure 3).

Figure 3:

\section{Does Saudi socialisation imbue traditional concepts of masculinity in children?}

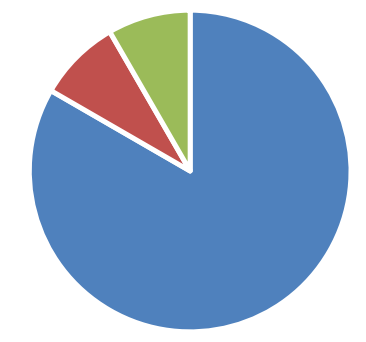

- Yes - Yes but Inconsequential - Changes Afoot

Many of the participants observed that traditional socialisation practices were responsible for the patriarchal society in Saudi Arabia, drawing attention the way parentsdifferentiate between the genders and enforced traditional gender roles. Most argued that these practices made way for absolute male authority from the onset, which could lead to abuse of power against women because both genders are raised with the belief that men are superior to women. The participants noted that this attitude is first instilled in males through their relationship with their sister and it eventually pervades all aspects of life, whether professional or personal.Many of the participants felt that it was important to change the way the sons and daughters were raised, and they should be treated equally if attitudes towards patriarchy and masculinity were to ever change.

A small number of the interviewees felt that patriarchal practices had positive advantages to it(see Figure 3), such as protecting and supporting women. However, the interviewees emphasised that it is important to explain the exact nature of the responsibility that men have towards women so there is no room for the kind of misinterpretation that allows men to oppress and suppress women.

\section{Imbalance of Gender Relationships}

In continuing with the theme of imbalance in gender relationships in Saudi society, the interviewees were asked about the balance of power in marital relationships and the cultural psychology behind it. Most of the participants argued that marital relationships within the Saudi construct are imbalanced, with the scales tipped in favour of the man(see Figure 4). They also noted that this imbalance of power could be attributed to domestic violence against women in the country. The overall argument was that Saudi society grants men power and authority in marital dynamics, disempowering women whilst empowering men misuse it to their advantage. 


\section{Figure 4:}

\section{Does the imbalance between genders in marital relationships play a role in constructing masculinity?}

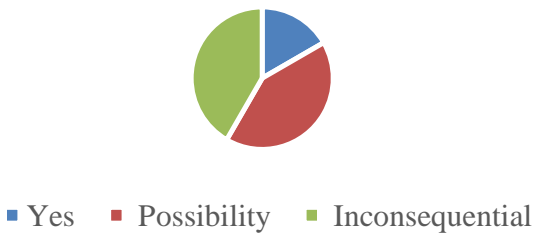

A few of the participants ave surprising responses to this questionas they believed that imbalance of power and authority in marital relationships was not of any particular concern. For some, the imbalance of power and authority was natural and in other instances, they believed that increasing balance in marital relationship had the potential to do more damage as there are men in society who would be unable to cope with the loss of authority and it could to more divorces and unhappy marriages. Attitudes such as these present a problem in that they contribute to continuation of male dominance and traditional constructs that confine women to the private sphere, which makes it easier to suppress them.

\section{Overall Impact of Vision 2030}

All the participants agreed that reforms brought in by Vision 2030 had marked the beginning of the journey for female empowerment in Saudi Arabia (see Figure 5). The interviewees believed that the increase in opportunities for education and employment has led to women to become more independent and self-sufficient. In addition to this, women's entry into the political arena has led to the improvement of women's status in Saudi society. However, theyalso acknowledged that there is still much that needs to be done and more often than not, they face cultural obstacles on the road to equality.

\section{Figure 5:}

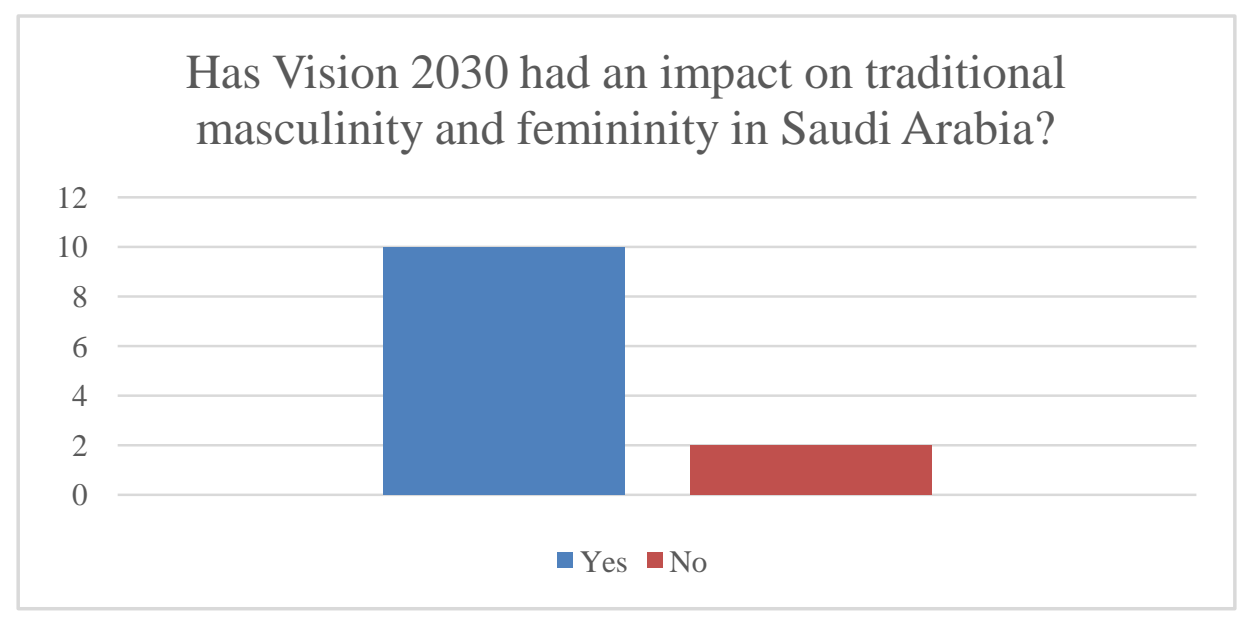

\section{Discussion}

From the interviews, three significant themes emerged: 1) the role of women in perpetuating masculinity; 2) the role of society in constructing archetypal masculinity; and 3)masculine opposition to the aims of Vision 2030.

\section{Women Perpetuating Masculinity}

Based on their responses, most participants indicated that differential treatment of children by mothers, including themselves, contributes the widespread presence of masculinity. Though some of the participants attempt to treat their male and female children equally, nevertheless, they are also still fixated on the idea that brothers are responsible for protecting their sisters. 
According to one participant, Ruwaida, the process of socialisation is an important component inconstructing the understanding of masculinity in boys. She points out that mothers constantly tell their sons that "You're the man", "You do everything", "You are the male head of the household" or "You can do whatever". This idea has buttressed the notion that archetypal masculinity is a positive role within the family construct as it is associated with the notion of protection and defense. Likewise, Rana, another interviewee, explained that "Women are also equally part of the problem, which also reinforces masculine values. I mean many of them will tell their son, "You're a boy, you're supposed to bear responsibility" whilst discouraging girls by repeatedly stating that girls are "weak therefore she is incapable of many things". In this way, they create an environment in which men truly believe they are superior to women, while women are encouraged to meekly tolerate these attitudes and believe they are the lesser sex.

This is why the home environment is integral in socialisation and can play a signifcant role in the reducing the proliferation of patriarchy in Saudi society. By the same token, Reema, notes that the differentiation between men and women is "our mistake ... The situation boils down to this, who is raising the male? We mothers are. So, don't raise a boy to be a male but rather a gentleman, who will consider a woman his equal". Reema also feels that if both genders are made responsible and held accountable for their own actions, and therefore are given the same rights, then it has the potential to change the nature of society and eventually end patriarchy as "the little changes can have a big impact". In the same vein, two other participants, Fatima and Arwa, share similar perspectives regarding women's contribution to patriarchy as they both believe that women have become the torchbearers of masculinity and patriarchy when they distinguish between their children, and place their sons as seconds-in-command to their fathers. Their behavior in enabling their sons to acquire power with minimal responsibility and assigning archetypal 'feminine' duties to their daughters has led to crystallization of masculinity in Saudi society.

This sets in motion a continuous cycle where their children, without a transformative external catalyst, will imbibe values of masculinity in their daily lives, influencing their own children and the cultural values that skew in favour of males will be imbued in future generations. Some of the participants commented that while current practices of socialisation contribute to create masculinity for boys, attitudes have begun to change. Safiya and Hannan both noted that though there are still issues that need to be addressed regarding the discrimination between the genders, there are is hope for the future. Hannan citedexamples of mothers who have begun to "raise their children as equals". While, they do continue to promote the idea "that the brother is the protector of his sister" but that does not mean that the boy has authority or rights over his sister nor can he make decisions on her behalf. Safiya detailed how in some Saudi familiesgirls are now free to express their opinions and families do take note and give consideration to their ideas.

\section{Society Constructing Masculinity}

Many of the participants noted the distinction and divide between the genders were created by society as a way to oppress women. Samiya felt that the lines drawn between men and women were because of a mindset that granted men "absolute authority and control due to culture and governance" and that immediate cultural values affect belief more than religion, which is often incorrectly cited as the source of female oppression. Her position is echoed by Salwa, who states that "The way we are brought up has caused differences to arise" and Shereen, who pointed out that "Religion does not differentiate between men and women", which poses that men and women are different to complement one another, but "society has" popularised the notion that "man is more powerful due to physiology".Fayza, who has a similar take on the matter, suggests that this is done so that men have more social and financial mobility as well as physical freedom, so they are the only ones in a position to make decisions while women are rendered dependent in order to further the male agenda. The issue of female oppression is more pronounced in Saudi Arabia, as women have always been under the power of the male dominion of the society (Rajkhan, 2014). They were not allowed to be involved in any kind of independent social or economic affairs and, historically, their decisions were not at all considered valuable in or for the society (Sadi\& Al-Ghazali, 2012). Moreover, Saudi society strongly adhered to the belief that a man who has committed transgressions in the past (even if at stood directly opposed to religious codes) is at most 'naughty' and can therefore be forgiven, while a woman's actions are held against her for life and society does not forgive nor forget.

A great deal of the daily and subtle obstacles arise for women in the form of a Saudi man's personality. Nearly all the participants could give examples and instances where these double standards transpire. In fact, all of the participants narrated incidents and events that clearly indicate the role culture plays in constructing masculinity, which eventually imbibes itself in the socialisation process. Due to socialisation, many Saudi men's values are riddled with contradictions and double-standards, whereby men are free to do as they please whereas women are not. Arwa explains that this attitude manifests itself in a variety of ways. She cited the example of how many husbands do not feel the need to call their wives if they won't be making it home nor do they need to have curfews but in turn they have the right to demand and know their wives' whereabouts at all times, who are also expected to be home by certainhour. 
Arwa added that this attitude is supported by Saudi culture, thus "men are free to return as and when they please, whilst women must have permission to go out of their homes and provide her husband with minute details about her excursions".

Samiya cites her own husband as an example, who forbids her from interacting with foreign men while he himself is free to talk, interact and, to an extent, physically engage with foreign women. Similarly, Rana gave her friend's husband as an example. She noted the double standard that exists within their relationship, as her friend's husband often opts to go on holidays outside of Saudi Arabia, leaving his wife and children behind but when she wishes to do the same, she must ask for his permission which is often refused. In both instances, the demands and expectations placed on the women is a display of unchecked masculine dominance.

Masculine dominance as an obstacle is not limited just to wives, as it extends to daughters as well. Kamilla recalled how when her daughter told her that she wanted to be journalist, Kamila supported her daughter's ambitions but she knew that ultimately the decision lay with her husband and her opinion would be of no importance or consequence. Kamila explained that no matter what the legal system allows, it is "[her] husband's decision that matters" because he is the man, and therefore the head of the household" and subsequently her husband forced their daughter to change her planned discipline, and this is a mere snapshot of the power and control that cultural masculinity affords Saudi men.

Fatima shared a similar experience of masculinity. She first spoke of her daughter, who despite being an educated and professional woman with her own income, is not able to spend her money as she wishes except unless approved and authorised by her husband. Fatimah said that her daughter's husband often prevented her from exercising her independence even when it came to buying items for herself. Fatima recounted an incident, when her daughter and her husband went to buy an electronic device that she had wanted. Her husband took the reins and discussed the details of the item with the retailer, and did not give her a chance to give her input or opinion nor did he ask her about what she wanted from her device. He decided on the item, told her to give him her debit card and then asked her to go wait in the car, while he purchased the item for her because he is the man and therefore he should be the one in charge.

While Saudi legislation is increasingly given women autonomy, the issue remains that masculinity within culture prevents women from having their own agency. These mechanisms of masculinity and unchecked practices are rendered invisible, and it can be partly attributed to Saudi socialisation, constructed mainly by the culture, where men and women are raised with the belief that men are superior, have the right to rule and be dominant while women should be subservient and dependent. Masculinity and patriarchal cultural practices have such a stronghold in the Saudi society to the extent that women are unable to free themselves from the shackles of societal impositions.

\section{Masculine Obstacles to Vision 2030}

Arwa and Hannan are of the opinion that female empowerment is essential for the development and wellbeing of the society, an argument that frequently makes its way into academic literature (MacKinnon, 1989). Salwa mentioned that viaVision 2030, the Saudi government has implemented numerous laws and guidelines to empower the women in society and promote their rights in different social and economic fields. Shereen noted that the governmental support for the role of women within their society has positively increase the ability of women to challenge the dominance of masculine leadership and dominance, thus confronting the status quo of masculinity in Saudi Arabia. Lamiss also reverberated Shereen's observation, adding that women are now competing against men for professional positions, including managerial roles. According to her, there is also an increase in women succeeding professionally in comparison to men, especially in the field of education, from getting opportunities abroad to actively contributing to research and development.

Kamila has a similar view, whereby she acknowledged that while men used to monopolize roles of leadership, in recent years, women have taken on more professional challenges and have been successful. Women had been previously sequestered to the education sector but now their presence is increasing across all the fields and they are becoming partners in firms as these positions are no longer reserved just for men. Thus, various participants suggest that the governmental role was potent in empowering women. This empowerment has increased the rights of women to hold responsibilities that were previously reserved only for men. With all these changes, opportunities for women, as well as successes, it has led to resentment from certain quarters of society, most notably traditional males, and as such there is resistance to these changes, which ranges from passive-aggressive to actively aggressive.

The participants of these study had many examples of where material factors empowered them yet were hindered by the culture factors. For instance, when Salwa had to update her personal data at her workplace, she was asked to attach her national identity card to update the work database. Though completely unnecessary nor required, she was asked to cover her photo with a piece of paper, then scan in the document and send it via email. 
As per Salwa, this situation presents two distinct dilemmas that Saudi women face. Firstly, the current database in place is preventing women from updating their profiles directly by themselves. This problem is easily avoidable by implementing a system that does not require a physical update of records per se, which would erase the need physical profiles passing through male administration, an issue under the cultural expectation and practice of the male guardianship system.

Secondly, it raises the question as to why there is no female administrative department that would be able to deal with such concerns, thus eliminating the need for a male intermediary. Furthermore, the demand to conceal her image, highlights the ways in which Saudi society seeks to hide female identity in order to indirectly reinforce male superiority, that then perpetuates female dependency.

Fatima recounts a professional meeting between the female department and male department of a faculty. Though the female department was the older and established department with the female staff outranking their male counterparts in terms of seniority, they female department was more often than not silent spectators during the meetings and conferences.She recalled how the male colleagues would not give her an opportunity to speak or express her opinion. This situation was further hindered by the fact that the meeting between the two departments was taking place in two different locations via an audio-visual interface, due to the practice ofgender segregation that still exists in Saudi Arabia. Fatima observed that since society has raised men and women in the dominant and subordinate dynamic, respectively, it is naturally assumed that a man will take a position of leadership, who in turn tends to give his male subordinates a voice before even considering giving an opportunity to a female voice.

Ruwaida was also critical of the masculine opposition and attitudes that act as a method to diminish women. She explained that even though Saudi law now allows women to drive, society to seems to be working in tandem to defeat this initiative. Ruwaida narrated the number of incidents where fabricated videos, in earnest, have been sent through social media (from both men and women) that depict women as terrible drivers who are often involved in accidents, too emotional to drive well, and incapable of dealing with situations that 'need' men (such as aggressive encounters with fellow drivers). Ruwaida als spoke of other videos that intimate a similar attitude towards female drivers, except they are executed with a comedic slant. By ridiculing women who drive through jokes and comedy, it makes it harder to criticise these videos. Women are told that they are being overly sensitive over something seemingly harmless, when in fact it is method to undermine women and their aspirations for independence.Thus, it is detrimental to female selfesteem and the perception of women's abilities in the collective consciousness.

On a more discerning note, there is also active and aggressive opposition against female drivers by Saudi men. To express their distaste and anger at the change in law, many Saudi men opted to burn their female relatives' cars. There was no shortage of incidents like these, as Arwa recounted the frequency of news reports as well as her friend, whose car was burned by a relative, which her friend believed had been motivated by the legalisation allowing women to drive. On another occasion, another one of Arwa's friends had woken up in the middle of the night to find that her car had been set on fire and the police had to get involved. The vehemence and rage with which certain men have reacted to the driving laws that grants women independence and autonomy has been surprising to even those who had expected some form of opposition.

These reactions and responses are not isolated or anomalies but rather they are recurrent, indicative of the wider problem that stems from societal attitudes and beliefs. It is important to note that men's actions echo and are reflective of society's mostly widely-held beliefs, which is that men have all the rights and women do not need any, as women are considered extensions of men. This thought process needs to be addressed in the immediate environment from the onset, otherwise men will continue to be obstacles to female empowerment and it is unlikely that the situation for women will improve on a cultural level, regardless of changes in legislations and laws that grant women autonomy and independence.

\section{Conclusion}

While undoubtedly, the notions of masculinity have begun to change in Saudi Arabia in the wake of Vision 2030, there are still significant strides that need to be made. Legislations and laws are material factors that can have a significant baring but they have their limitations. They are first step that allows for cultural factors to be affected. Though this is a laborious process, there are ways to expedite these changes for the betterment of Saudi society.

The findings of this study suggest that women, men and society are responsible, to varying degrees, for creating masculinity within the context of Saudi Arabia. Therefore, challenges remain in the form of traditional mindsets, societal resistance and male resentment. This is where legislation only has limited effect and it requires a different kind of initiative that addresses the obstacles that masculinity presents to empowering women. 
While empowering women was essential in giving women the space to express their voice, it is also important to note that masculinity itself has to be addressed directly. Based on the discussion in the interviews, the following are possible recommendations to help combat masculinity on a cultural level:

1. There needs to be seminars, workshops and entertainment content that addresses masculinity from a male perspective. While Vision 2030 has undertaken extensive efforts to improve the quality of life for Saudi women and improve their status to the point they are considered equal to men in the political, legal and economic spheres, there are still cultural obstacles that impede women. To alleviate some of these obstacles, it is important to address masculine considerations as to why they believe and behave in traditional constructs. Where possible, it is important to present an alternative perspective that makes them reconsider some of their attitudes.

2. There ought to be parenting classes for both mothers and fathers to encourage and explain the importance of raising males and females as equals. Though, typically, it's a mother who has the most significant and immediate impact on a child's attitude, it is also important to note that impact that fathers can have too, albeit more subliminally. So, if women are adapting to a new way of thinking, it has to be supported by the male members of society too for it to truly take hold and this is where empowered women and empowering women can face roadblocks. Addressing socialisation requires an understanding of the role that parents play in a child's upbringing and in forming attitudes.

The above recommendations may appear to be passive in their approach but an aggressive strategy might result in the more traditional members of Saudi society feeling attacked to the point that they are unwilling to reconsider their notions of cultural norms. Methods such as the ones listed above address the problem at grassroot level without antagonising established status quo, which has a greater chance of begetting change that will lead to true equality for Saudi women.

\section{References}

Al-Khateeb, S.A.H. (1998) Women, family and the discovery of oil in Saudi Arabia. Marriage \& Family Review, 27(12), pp.167-189.

Almosaed, N.F. (2008) Money and Power in Saudi family. Journal of King Abdulaziz University: Arts \& Humanities, 6(2), pp.61-87.

Al-Rasheed, M. (2013) A Most Masculine State: Gender, Politics and Religion in Saudi Arabia. Cambridge, Cambridgeshire: Cambridge University Press.

Alsaleh, S. (2012)Gender Inequality in Saudi Arabia: Myth and Reality. International Proceedings of Economics Development \& Research, 39(1), pp.123-130.

Creswell, J.W. (2006) Qualitative Inquiry \& Research Design: Choosing Among the Five Approaches. $2^{\text {nd }}$ Edition. Thousand Oaks, CA: SAGE Publications.

Dietz, M.G. (2003) Current Controversies in Feminist Theory.Annual Review of Political Science, 6(1), pp.399-431.

Dobash, R.E. \&Dobash, R.P. (2003) Women, Violence and Social Change. Abingdon, Oxfordshire: Routledge.

Edward, Y. (2018) First Saudi Stadium Opens to Women to Watch Soccer. VOA News, [online] 12 January. Available at:https://www.voanews.com/middle-east/first-saudi-stadium-opens-women-watch-soccer[Accessed 29 September 2019]

Elamin, A.M. \&Omair, K. (2010) Males' attitudes towards working females in Saudi Arabia. Personnel Review, 39(6), pp.746-766.

Estimo Jr, C. (2017) Shoura to discuss recommendation for women to hold leadership positions in Saudi missions abroad. Arab News, [online] 27 November. Available at: https://www.arabnews.com/node/1200346/saudiarabia

Howitt, D. \& Cramer, D. (2005) Introduction to Research Methods in Psychology. $1^{\text {st }}$ Edition. Harlow, England: Prentice Hall.

Kelly, S. (2009) Overview Essay: Recent Gains and New Opportunities. In: S. Kelly, J. Breslin, T. Roylance\& M. Abdelnaby (2009) Women's Rights in the Middle East and North Africa: Gulf Edition. New York, NY: Freedom House. pp.1-8.

Kenny, E. J. \& Donnelly, R. (2018) Navigating the gender structure in information technology: How does this affect the experiences and behaviours of women?.Human Relations. Available at:https://doi.org/10.1177/0018726719828449 [Accessed 29 September 2019]

Kumar, R. (2005) Research Methodology: A Step-by-Step Guide for Beginners. Thousand Oaks, CA: SAGE Publications Ltd. 
Loyd-Roberts, S. (2016) The War on Women and Brave Ones Who Fight Back. $3^{\text {rd }}$ Impression Edition. London: Simon \& Schuster UK Ltd.

MacKinnon, C.A. (1989) Toward a Feminist Theory of the State. Cambridge, MA: Harvard University Press.

Marczyk, G., DeMatteo, D. \& Festinger, D. (2005) Essentials of Research Design and Methodology. Hoboken, NJ: John Wiley \& Sons Inc.

Mobaraki, A.E.H. \&Soderfeldt, B. (2010) Gender inequity in Saudi Arabia and its role in public health. East Mediterranean Health Journal, 16(1), pp.113-118.

Morse, J., Barrett, M., Mayan, M., Olson, K. \& Spiers, J. (2002) Verification Strategies for Establishing Reliability and Validity in Qualitative Research. International Journal of Qualitative Methods, 1(2), pp.13-22.

Neuman, W.L. (2010) Social Research Methods: Qualitative and Quantitative Approaches. $7^{\text {th }}$ Edition. London: Pearson.

Patton, M.Q. (1990) Qualitative Evaluation and Research Methods. Thousand Oaks, CA: SAGE Publications.

Rager, K. (2005) Self-Care and the Qualitative Researcher: When Collecting Data Can Break Your Heart. Educational Researcher, 34(4), pp.23-27.

Rajkhan, S. (2014) Women in Saudi Arabia: Status, Rights, and Limitations. MA. University of Washington Bothell. Available at: http://hdl.handle.net/1773/25576 [Accessed 29 September 2019]

Risman, B.J. (2017) 2016 Southern Sociological Society Presidential Address: Are Millennials Cracking the Gender Structure?. Social Currents, 4(3), pp.208-227.

Risman, B.J.\& Davis, G. (2013) From sex roles to gender structure. Current Sociology, 61(5-6), pp.733-755.

Sadi, M.A. \& Al-Ghazali, B.M. (2012) The Dynamics of Entrepreneurial Motivation Among Women: A Comparative Study of Businesswomen in Saudi Arabia and Bahrain. In: M.A. Ramady (ed). (2012) The GCC Economies: Stepping Up To Future Challenges. New York, NY: Springer. pp. 217-227.

Saudi Vision 2030 (2016) Saudi Vision 2030. Available at: https://vision2030.gov.sa/en[Accessed 29 September 2019]

Sharman J. (2017) Saudi Arabia to let women work and study without man's permission, The Independent, [online]6 May. Available at: https://www.independent.co.uk/news/world/middle-east/saudi-arabia-male-guardianshiprelax-women-work-study-gender-equality-a7721641.html[Accessed 29 September 2019]

Stevenson, P. (2018) Empowerment Discourses in Transnational Sporting Contexts: The Case of Sarah Attar, The First Female Saudi Olympian. Sociology of Sport Journal, 35(3), pp.238-246.

Stiles, W. (1993) Quality Control in Qualitative Research. Clinical Psychology Review, 13(6), pp.593-618. 